\title{
Characterisation of a naturally occurring mutation (L107I) in the HNF1 $\alpha$ (MODY3) gene
}

\author{
C. Cervin 1 , M. Orho-Melander ${ }^{1}$, M. Ridderstråle ${ }^{1}$, M. Lehto ${ }^{2}$, S. Barg ${ }^{3}$, L. Groop ${ }^{1}$, C.M. Cilio ${ }^{1}$ \\ 1 Department of Endocrinology, Wallenberg Laboratory, Malmö University Hospital, Malmö, Sweden \\ 2 Department of Molecular Medicine, National Public Health Institute, Helsinki, Finland \\ ${ }^{3}$ Department of Physiological Sciences, BMC F11, Lund University, Lund, Sweden
}

\section{Abstract}

Aims/hypothesis. Maturity onset diabetes of the young type 3 (MODY3) is a monogenic form of diabetes mellitus caused by mutations in the gene encoding for hepatocyte nuclear factor 1 alpha, HNF1 $\alpha$. In this study we have examined the in vivo and in vitro effects of a mutation (L107I) outside the DNA binding and dimerization domains in the $\mathrm{N}$ terminal part of the $H N F 1 \alpha$ gene.

Methods. Beta-cell function of the affected family members was assessed by an oral glucose tolerance test. Functional tests were carried out to explain the role of the mutation in vitro by transcriptional activity assay, Western blotting, DNA-binding assays and subcellular localization experiments.

Results. Affected family members showed an $86 \%$ decreased insulin response to glucose when compared to age-matched healthy control subjects. In vitro the mutation showed a $79 \%$ decrease in transcriptional activity as compared to wild type HNFl $\alpha$ in HeLa cells lacking $H N F 1 \alpha$. The transcriptional activity was not suppressed when the mutant was co-expressed with wild type HNF1 $\alpha$ suggesting that the decreased activity was not mediated by a dominant negative mechanism. The L107I/HNF1 $\alpha$ protein showed normal nuclear targeting but impaired binding to an HNF1 $\alpha$ consensus sequence.

Conclusion/interpretation. Our results suggest that the L107I substitution represents a MODY3 mutation which impairs beta-cell function by a loss-of-function mechanism. [Diabetologia (2002) 45:1703-1708]

Keywords MODY, Type II diabetes, HNF $1 \alpha$, gene expression, DNA binding, cell lines, mutation, metabolism, insulin.
Maturity onset diabetes of the young (MODY) is a monogenic form of diabetes mellitus with autosomal dominant inheritance. It is characterised by early onset and impaired insulin secretion with minimal or no defect in insulin action [1]. There are at least six different types of MODY, MODY3 being the most common form resulting from mutations in the gene encoding the transcription factor hepatocyte nuclear factor $1 \mathrm{al}-$

Received: 6 June 2002 / Revised: 5 August 2002

Published online: 19 October 2002

(C) Springer-Verlag 2002

Corresponding author: L. Groop, MD, PhD, Department of Endocrinology, Malmö University Hospital, S-205 02 Malmö, Sweden. E-mail: leif.groop@endo.mas.lu.se

Abbreviations: HNF1 $\alpha$, hepatocyte nuclear factor 1 alpha; EMSA, electophoretic mobility shift assay. pha $(H N F 1 \alpha)$ [2-7]. HNF1 $\alpha$ is a homeodomain containing transcription factor expressed in several tissues including the liver, kidney, pancreas and gut $[8,9,10]$. The protein regulates a number of liver specific genes as well as genes involved in glucose metabolism (e.g. L-type pyruvate kinase) and glucose transport (e.g. GLUT2) [11, 12]. HNF1 $\alpha$ is composed of three known functional domains: an N-terminal dimerization domain (amino acids 1-32), a DNA-binding domain with pseudo-Pou and homeodomain motifs (amino acids 150-280) and a C-terminal transactivation domain (amino acids 281-631) [13]. The function of the region between amino acids 100-150 is not entirely clear but could be involved in DNA recognition [14]. HNF $1 \alpha$ binds to DNA as a homodimer or heterodimer with the structurally related HNF1 $\beta$ protein [15]. Although mutations associated with MODY3 
have been found in all regions of the HNFl $\alpha$ including the promoter region most of them seem to affect the DNA binding domain and particularly a mutational hotspot in exon $4[16,17]$. The relation between the location of the mutations and the MODY3 phenotype is not straightforward. Proteins with amino acid substitutions inhibiting DNA-binding have been shown to form non-functional homodimers with the wild-type protein, either by haplo-insufficiency or dominantnegative mechanisms [13]. Whether there is a relation between the MODY3 genotype and phenotype, i.e. whether there are "milder" mutations outside the DNA binding domain, is a hypothesis that is open to question. To address this, we investigated the biological consequences of a mutation at codon 107 , between the dimerization and DNA binding domain in the $H N F 1 \alpha$ gene, which segregates with diabetes in a Swedish MODY family.

\section{Materials and methods}

In vivo studies: subjects. A family from southern Sweden carrying a mutation causing a substitution of leucine with isoleucine (L107I) in the HNF $1 \alpha$ gene has been described previously [18]. The family included eight mutation carriers in three generations.

Subjects were challenged by a $75 \mathrm{~g}$ oral glucose tolerance test (OGTT). Blood samples for measurements of plasma glucose and serum insulin concentrations were drawn at $-5,0,30$, 60 and $120 \mathrm{~min}$. We used the insulin over glucose ratio as a measure of the insulin response at a given glucose concentration. For three patients requiring insulin therapy, no OGTT was carried out and beta-cell function was instead assessed as insulin/C-peptide response $6 \mathrm{~min}$ after i.v. injection of $0.5 \mathrm{mg}$ glucagon [19]. Plasma glucose was measured with a glucose oxidase method using a Beckman Glucose Analyzer II (Beckman Instruments, Fullerton, Calif., USA) and insulin was measured with ELISA (DAKO, Cambridgeshire, UK) with an interassay $\mathrm{CV}$ of $8.9 \%$. Age-matched non-diabetic subjects $(n=66)$ and patients with Type II (non-insulin-dependent) diabetes mellitus ( $n=48$ ) without MODY mutations served as control subjects for the OGTT. Data from eight non-diabetic subjects were used as reference values for the glucagon test. Fasting blood samples were drawn for measurements of serum total cholesterol, HDL-cholesterol and triglycerides. To calculate waist-to-hip ratio, waist circumference was measured midway between the lowest rib and the iliac crest and hip circumference was measured over the widest part of the glutereal region. For blood pressure records the mean of three measurements were calculated after $30 \mathrm{~min}$ of rest at 5-min intervals. Studies were approved by local ethics committees.

In vitro studies: plasmid constructs. In vitro mutagenesis was carried out on full-length human $H N F 1 \alpha$ cDNA using a QuickChange Site-Directed Mutagenesis Kit (Stratagene, La Jolla, Calif., USA). The oligo-nucleotide used in mutagenesis was 5'-GCCGTGGTGGAGACCA ATTCTGCAGGAGGACC-3', with the mutated nucleotide underlined corresponding to the L107I substitution. Wild type and mutant $H N F 1 \alpha$ were subcloned into a pcDNA3.1 expression vector (Invitrogen, NV Leek, Netherlands). Sequences of the created constructs were verified by DNA sequencing before expression studies.
Transactivation assay. HeLa cells (lacking HNF1 $\alpha$ ) were maintained in a DMEM media supplemented with $10 \%(\mathrm{v} / \mathrm{v})$ foetal bovine serum, $1.2 \%(\mathrm{v} / \mathrm{v})$ Penicillin/Streptomycin and $1.4 \%(\mathrm{v} / \mathrm{v})$ L-Glutamin. MIN6 cells (expressing mouse $H N F 1 \alpha$ ) were maintained in DMEM/F12Ham media supplemented with $10 \%(\mathrm{v} / \mathrm{v})$ foetal bovine serum, $1.2 \%(\mathrm{v} / \mathrm{v})$ Penicillin/Streptomycin and $1.4 \%(\mathrm{v} / \mathrm{v})$ L-Glutamin and $1 \%(\mathrm{v} / \mathrm{v})$ non-essential amino acids. $1.5 \times 10^{5} \mathrm{HeLa}$ cells or $3 \times 10^{5}$ MIN6 cells were transfected using Lipofectamine plus Reagent (Life Technologies, Rockville, Md., USA) with indicated amounts of wild type or mutant $H N F 1 \alpha$-pcDNA3.1 together with 0.5 or $2 \mu \mathrm{g}$ GLUT2/pGL3-basic luciferase vector (Promega, Madison, Wis., USA) and 25 or $100 \mathrm{ng}$ pRL-TK internal control vector (Promega), respectively. The transcriptional activity was measured after $24 \mathrm{~h}$ (HeLa) or $48 \mathrm{~h}$ (MIN6) using the Dual Luciferase Assay System (Promega) and Victor ${ }^{2}$ Wallac 1420 Multilabel counter (PerkinElmer, Stockholm, Sweden). The dual luciferase assay results were from three independent experiments, each carried out in triplicate and calculations of transcriptional activity in percentage was done by subtracting the value of the empty vector.

Western blot analysis. $1.2 \times 10^{6} \mathrm{HeLa}$ cells and $2.8 \times 10^{6}$ MIN6 cells were transfected using Lipofectamine plus Reagent (Life Technologies) with $5 \mu \mathrm{g}$ of wild type or mutant HNF1 $\alpha$ pcDNA3.1 construct. After $24 \mathrm{~h}$, whole cell extracts were prepared using RIPA lysis buffer $(50 \mathrm{mmol} / \mathrm{l}$ Tris- $\mathrm{HCl}(\mathrm{pH} 8)$, $150 \mathrm{mmol} / \mathrm{l} \mathrm{NaCl}, 1 \% \mathrm{NP}-40,0.5 \%$ deoxycolate, $1 \mathrm{mmol} / \mathrm{l}$ sodiumorthovanadate, $15 \mu \mathrm{g} / \mathrm{ml}$ aprotinin, $1 \mathrm{mmol} / \mathrm{l}$ phenylmethylsulphonyl fluoride). $5 \mu \mathrm{g}$ of total protein was subjected to SDS-PAGE (10\%) and transferred to Hybond-P membranes (Amersham Pharmacia Biotech, Uppsala, Sweden). After blocking the membranes for $1.5 \mathrm{~h}$ with $5 \%$ milk powder and $0.05 \%$ Tween-20 in Tris buffered saline, the membranes were incubated with anti-HNF1 $\alpha(\mathrm{N}-19)$ (Santa Cruz Biotechnology, Santa Cruz, Calif., USA) or anti-HNF1 (BD Bioscience, San Diego, Calif., USA) for $1 \mathrm{~h}$ followed by a horseradish peroxidase conjugate anti-goat IgG (Santa Cruz Biotechnology) or anti-mouse IgG (Amersham Biosciences AB, Uppsala, Sweden) for $1 \mathrm{~h}$. The antibody binding was visualized using Supersignal West Pico Chemiluminescent Substrate (Pierce, Rockford, Ill., USA).

Electrophoretic Mobility Shift Assay (EMSA). $1.2 \times 10^{6} \mathrm{HeLa}$ cells were transfected with $5 \mu \mathrm{g}$ of wild type or mutant $H N F 1 \alpha$-pcDNA3.1 using Lipofectamine plus Reagent (Life Technologies). After $24 \mathrm{~h}$, nuclear protein extracts were prepared as previously described [20] and $4.0 \mu \mathrm{g}$ of extracted proteins were incubated with a $27 \mathrm{bp}{ }^{32} \mathrm{P}$-labelled oligonucleotide probe $(\sim 50,000 \mathrm{cpm})$, containing the GLUT2 promoter HNF1 $\alpha$ binding site sequence (CTCAGTAAAGATTAACCAT). Samples were incubated at room temperature for $20 \mathrm{~min}$ in a buffer containing $10 \mathrm{mmol} / \mathrm{l} \mathrm{HEPES}(\mathrm{pH} 7.9$ ), $60 \mathrm{mmol} / \mathrm{l} \mathrm{KCl}$, $0.1 \mathrm{mmol} / 1$ EDTA, $10 \%$ glycerol, $15 \mathrm{mmol} / 1$ dithiothreitol and $150 \mathrm{ng}$ poly $\mathrm{dI}-\mathrm{dC}$. The complexes were shifted with addition of $1 \mu$ l anti-HNF1 $\alpha(N-19) X$ (Santa Cruz Biotechnology). The DNA-protein complexes were separated on a $4 \%$ polyacrylamide gel and visualized by autoradiography.

Immunolocalization studies. HeLa cells $\left(0.8 \times 10^{5}\right)$ grown on Falcon Culture slides (Becton Dickinson Labware, Bedford, Mass., USA) were transfected with $1.0 \mu \mathrm{g}$ of wild type/HNF1 $\alpha$ and L107I-HNF $1 \alpha$ using Lipofectamine plus Reagent (Life Technologies). Transfected cells were fixed with methanol after $48 \mathrm{~h}$ and blocked with PBS containing 5\% Normal Donkey Serum, NDS (Jackson Immuno Research, West Grove, Pa., USA) for $15 \mathrm{~min}$. The primary antibody, anti-HNF1 (BD Bio- 
science), and the secondary antibody, anti-mouse Cy3 (Jackson Immuno Research), were diluted in PBS + 5\% NDS and incubated for $2 \mathrm{~h}$ and $1 \mathrm{~h}$, respectively. Fluorescence was examined using a fluorescence microscope (TRITC filter) with a digital camera (Nikon Eclipse 800, Nikon, Tokyo, Japan).

Statistics. Data are shown as means \pm SEM or SD. A $p$ value of less than 0.05 was considered statistically significant. At each time point of the OGTT, statistical comparisons were carried out by Mann-Whitney U test (SAS Institute Inc., Cary, N.C., USA).

The Dual Luciferase assay results were from three independent experiments, each carried out in triplicate; differences were calculated with paired Student's $t$ test.

\section{Results}

Clinical characteristics of L107I-carriers. The pedigree of the affected family is shown in Fig. 1 with the age at onset indicated for the diabetic subjects. All mutation carriers developed diabetes between the age of 18 and 38 years. The clinical and anthropometric data from the affected MODY patients, Type II diabetic patients and healthy control subjects are given in Table 1. The insulin over glucose ratio (calculated from the incremental area) during the OGTT was $86 \%$ lower in carriers of the L107I substitution compared to control subjects. At 30,60 and $120 \mathrm{~min}$ of the OGTT the insulin over glucose ratios were reduced $(p<0.005)$ in the L107I-carriers. The differences were not significant between the L107I-carriers and the Type II diabetic patients. As expected, the Type II diabetic patients had a lower insulin/glucose ratio than the control subjects ( $p<0.005$ Fig. 2). The incremental insulin responses to glucagon were reduced by $46 \%$, $91 \%$ and $82 \%$ in the three insulin-treated patients compared with the mean $( \pm \mathrm{SD})$ of healthy control subjects $(58,9,20$ vs $108 \pm 30 \mathrm{pmol} / \mathrm{l}$ in control subjects subjects).

Impaired transcriptional activity of HNFl $\alpha$ containing the L107I substitution. To characterise the func-

Table 1. Clinical characteristics of patients carrying the L107I-HNF1 $\alpha$ mutation, age-matched patients with diabetes and healthy controls individuals

\begin{tabular}{lcll}
\hline & $\begin{array}{l}\text { L107I- } \\
\text { carriers }\end{array}$ & $\begin{array}{l}\text { Type II } \\
\text { diabetic } \\
\text { patients }\end{array}$ & $\begin{array}{l}\text { Control } \\
\text { subjects }\end{array}$ \\
\hline Subjects $(\mathrm{m} / \mathrm{f})$ & $8(6 / 2)$ & $48(22 / 26)$ & $66(26 / 40)$ \\
Age at onset $(\mathrm{yr})$ & $23.5 \pm 5.8$ & $28.4 \pm 8.0$ & \\
$\mathrm{BMI}\left(\mathrm{kg} / \mathrm{m}^{2}\right)$ & $25.3 \pm 3.5$ & $27.7 \pm 7.2$ & $24.2 \pm 3.5$ \\
WHR $(\mathrm{male})$ & $0.88 \pm 0.04$ & $0.94 \pm 0.08$ & $0.91 \pm 0.07$ \\
Systolic BP $(\mathrm{mmHg})$ & $139 \pm 17$ & $125 \pm 14$ & $118 \pm 12$ \\
Diastolic BP $(\mathrm{mmHg})$ & $75 \pm 11$ & $79 \pm 12$ & $72 \pm 9$ \\
Cholesterol $(\mathrm{mmol} / \mathrm{l})$ & $4.74 \pm 0.54$ & $5.12 \pm 1.12$ & $4.73 \pm 0.87$ \\
Triglycerides(mmol/l) & $0.96 \pm 0.20$ & $1.52 \pm 1.03$ & $1.04 \pm 0.57$ \\
HDL-cholesterol (mmol/l) & $1.18 \pm 0.30$ & $1.28 \pm 0.32$ & $1.42 \pm 0.31$ \\
\hline & & &
\end{tabular}

Results are given as means $\pm \mathrm{SD}$

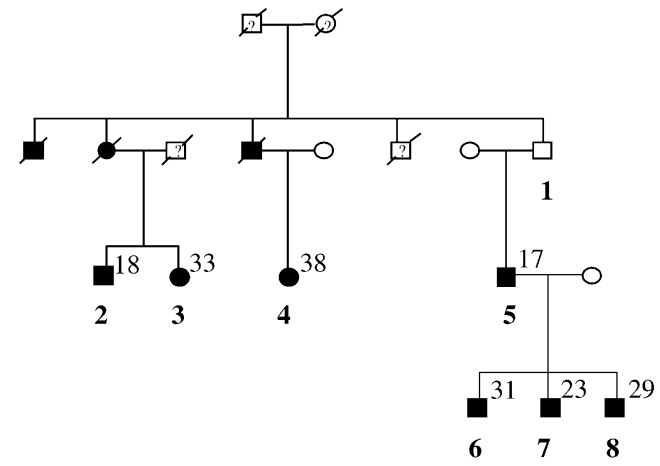

Fig. 1. Pedigree of the MODY3 family. Squares represent males and circles females, diabetic patients are indicated with filled symbols. Patients 1-8 have been previously shown to be carriers of the L107I substitution in HNF1 $\alpha$. Age at onset of diabetes is shown at the upper right corner of the symbol

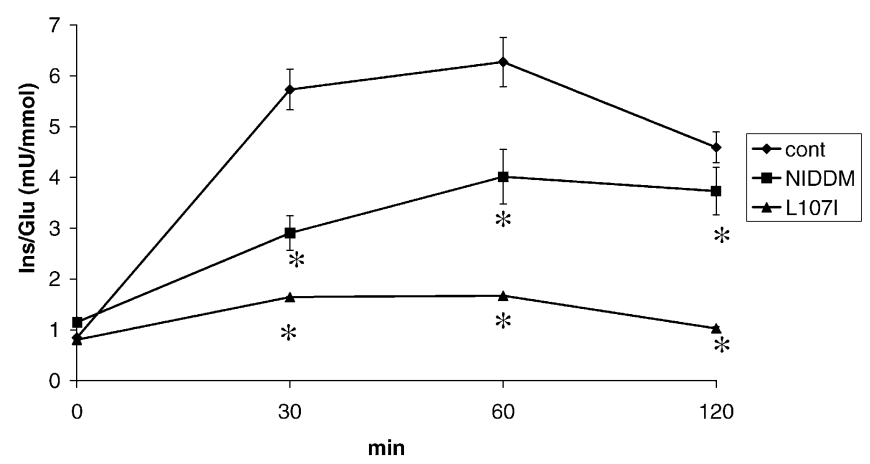

Fig. 2. Insulin secretion during an OGTT. Three of the affected family members $(6,7,8)$ were compared with 66 agematched control subjects and 48 age-matched diabetic patients ( \pm 5 years). Results are given as means \pm SEM and $*$ indicates $p<0.005$

tional consequences of the L107I mutation in vitro, we compared the ability of the L107I-HNF1 $\alpha$ protein to activate the human GLUT2 promoter with that of the wild type protein. Transcriptional activity of the mutated HNFl $\alpha$ in HeLa cells (lacking endogenous $H N F 1 \alpha$ ) was reduced by $79 \%$ compared with the wild type $(0.11 \pm 0.02$ vs $0.51 \pm 0.01 ; p<0.005$, Fig. $3 \mathrm{~A})$. In contrast, transcriptional activity was normal when tested in MIN6 cells that express the corresponding mouse HNF1 $\alpha$ (Fig. 3B). To examine whether the mutation could have a dominant-negative effect on wild type $H N F 1 \alpha$ in HeLa cells, increasing amounts of the L107I-HNF1 $\alpha$ were transfected together with $50 \mathrm{ng}$ of wild type $H N F 1 \alpha$. No dominant-negative effect was observed (Fig. 3C). Western blot analysis confirmed equal expression of the mutated and wild type protein (Fig. 4A).

Impaired DNA-binding of HNF1 $\alpha$ with the L107I substitution. An electrophoretic mobility shift assay (EMSA) was carried out to analyse the DNA-binding capacity of the mutated L107I-HNF1 $\alpha$ protein. The 
mutant protein showed lack of DNA binding as depicted in Fig. 5A, although in some experiments minimal binding activity was detected (data not shown). Gel shift specificity was examined using anti-HNF1 $\alpha$ antibody, which is shown in Fig. 5A by a clear supershift of the complex.
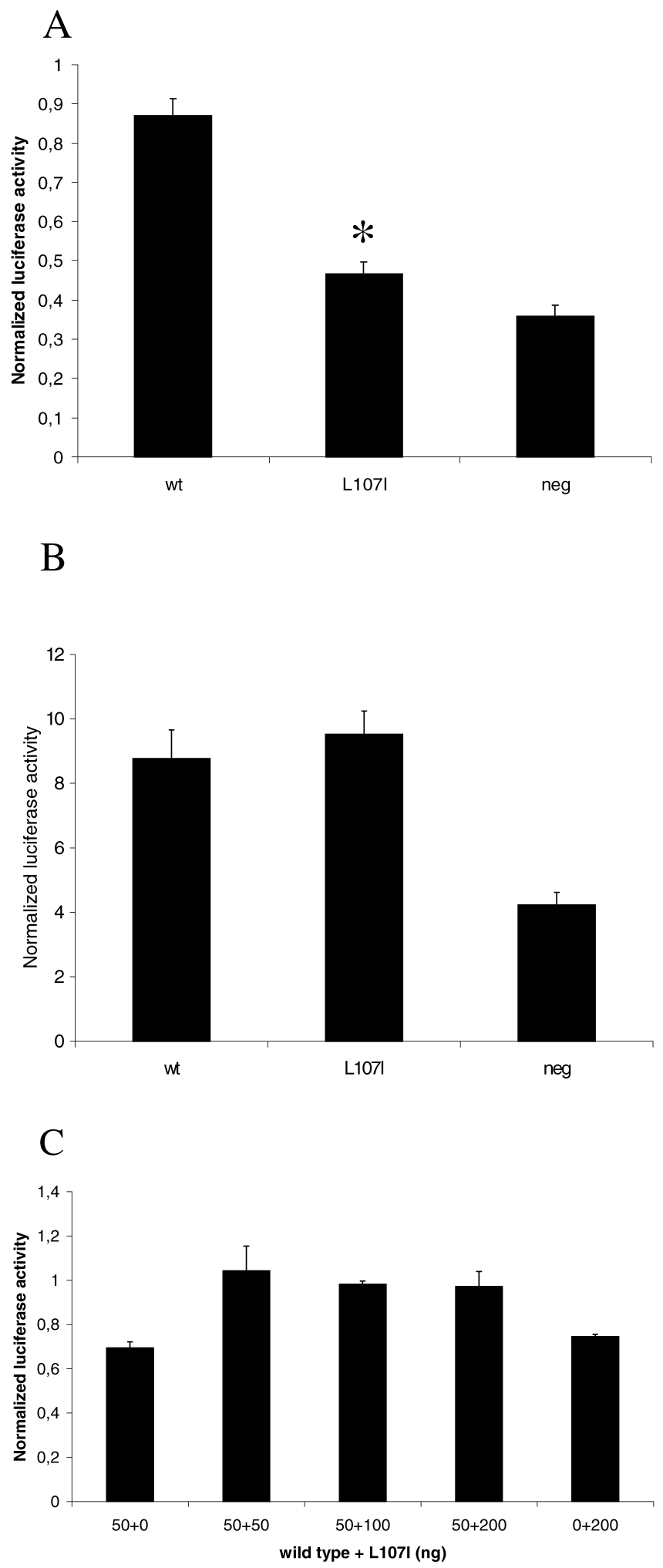

Nuclear translocation of HNFl $\alpha$ is not impaired by the L107I substitution. To examine whether the L107I substitution affects nuclear translocation of the HNF1 $\alpha$ protein we carried out intracellular localization studies using immunostaining. HeLa cells were transfected with either wild type HNF1 $\alpha$ or L107I$H N F 1 \alpha$ and the subcellular location was assessed by fluorescence microscope (Fig. 6). The nuclear signals

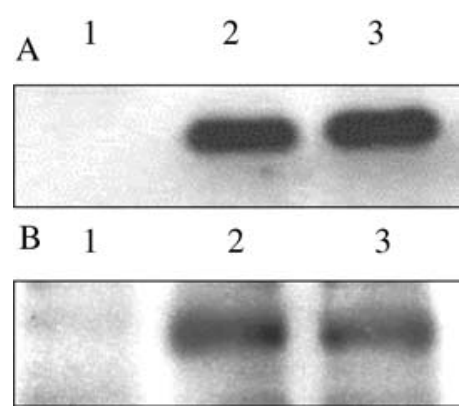

Fig. 4A, B. Western blot analysis and immunodetection of HNF1 $\alpha$ from transfected HeLa cells, $\mathbf{A}$ whole cell lysate $\mathbf{B}$ nuclear extracts. Lane 1, empty vector; lane 2, wild type HNF1 $\alpha$; lane 3, L107I-HNF1 $\alpha$

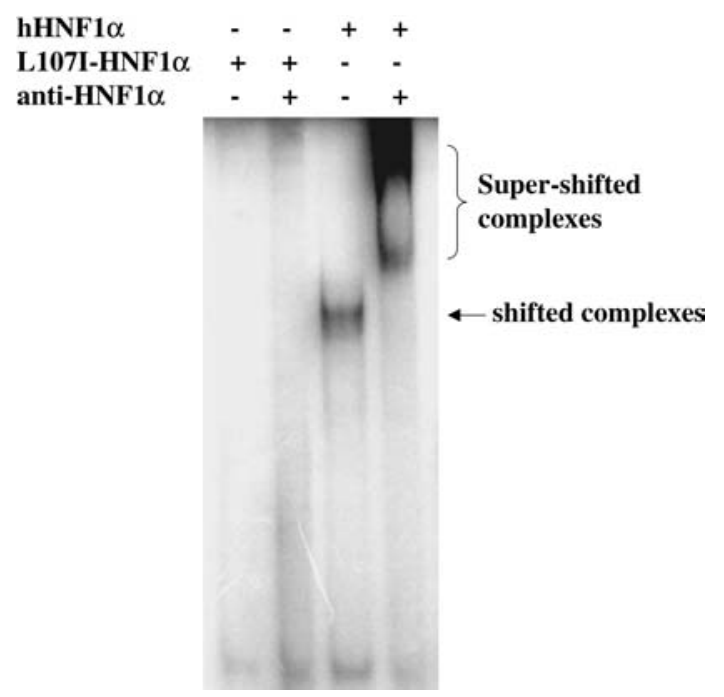

Fig. 5. DNA-binding ability of wild type and mutated HNF1 $\alpha$ to the binding sequence of GLUT2 promoter by EMSA analysis

Fig. 3A-C. Transcriptional activation by wild type and mutant HNF1 $\alpha$. Luciferase activity was normalized by the activity of the internal control pRL-TK and the reporter construct contained the GLUT2 promoter. The results were from three independent experiments; means \pm SEM, *indicating $p<0.005$. A HeLa cells transfected with $50 \mathrm{ng}$ wild type, L107I-HNF1 $\alpha-$ pcDNA3.1 or empty vector. B MIN6 cells transfected with $100 \mathrm{ng}$ wild type, L107I-HNF1 $\alpha$-pcDNA3.1 or empty vector. C Wild type HNF1 $\alpha$-pcDNA3.1 (50 ng) and L107I-HNF1 $\alpha$ pcDNA3.1 $(0,50,100,200 \mathrm{ng})$ was cotransfected to examine a possible dominant negative effect by the mutated protein. Total amount of DNA added was adjusted to $250 \mathrm{ng}$ with empty vector 


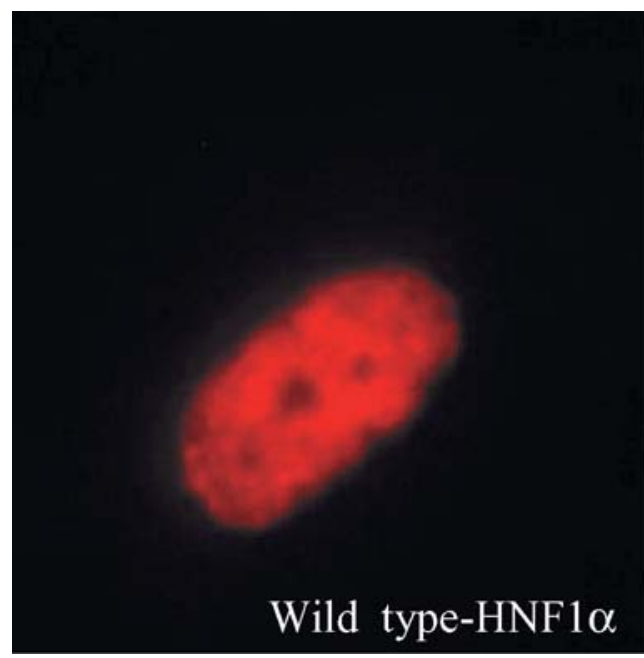

Fig. 6. Subcellular localization of the HNF1 $\alpha$ by immunostaining showing correct targeting of both wild type- and L107I-HNF1 $\alpha$ to the nucleus. Magnification is $\times 40$

of HeLa cells transfected with wild type or mutated HNF1 $\alpha$ did not differ, indicating that the L107I substitution does not impair nuclear translocation. We further confirmed equal expression of both wild type and mutant protein in nuclear extracts by Western blot analysis (Fig. 4B).

\section{Discussion}

The mutation causing the L107I substitution in the $H N F 1 \alpha$ gene was identified in a typical MODY family with a dominant mode of inheritance and age at onset of diabetes less than 25 years in at least two family members. This substitution has not been described in other MODY families, Type II diabetic patients or in a group of non-diabetic control subjects [18]. No mutations in other MODY genes were observed in the affected family members. It is therefore likely that this mutation caused diabetes in this family [18]. The clinical phenotype was also similar to the phenotype described in MODY3 patients [21] with markedly impaired beta-cell function and normal insulin sensitivity. In addition, their serum lipid profile was much better than that seen in patients with the common form of Type II diabetes.

Substitution of leucine with another nonpolar hydrophobic amino acid isoleucine at codon 107 results in only moderate changes in the primary structure of the HNF1 $\alpha$ protein but could theoretically influence its secondary structure as hydrophobic interactions between amino acids are important for protein structures. Moreover, since this amino acid residue has been shown to be conserved between different species [22] it is therefore likely to be important in maintaining the tertiary structure and integrity of the protein. The role of the intermediary region between the dimerization

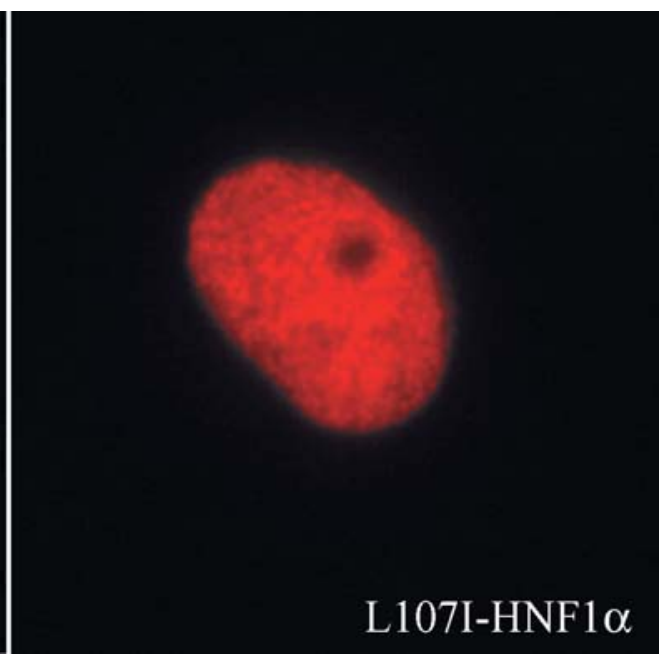

and DNA binding domain, where the L107I substitution is located, remains somewhat elusive but it has been ascribed a role in DNA recognition [14, 23]. Our data clearly showed that a leucine for isoleucine substitution at codon 107 results in impaired DNA binding and reduced transcriptional activity in HeLa cells. It is not likely that decreased transcriptional activity would be a consequence of the experimental conditions as both the mutated and wild type HNF1 $\alpha$ showed equal amount of expressed proteins.

In MIN6 cells, in contrast to HeLa cells which do not contain endogenous HNF1 $\alpha$, transcriptional activity was normal suggesting that endogenous HNF1 $\alpha$ is able to compensate for the effect of the mutated protein and that the mutation works in a loss-of-function manner. This is most likely due to haploinsufficiency as HeLa cells transfected with increasing amounts of the mutated L107I-HNFI $\alpha$ together with wild type $H N F 1 \alpha$ did not show impaired transcriptional activity as would be expected if the mutation would operate in a dominant negative manner.

Other studies of mutations in this region, e.g. a P112L substitution show an association with reduced DNA-binding and normal nuclear targeting [24], while a Y122C substitution shows reduced DNAbinding together with reduced protein content in the nucleus, reduced protein stability but with a correct targeting of HNF1 $\alpha$ to the nucleus [25]. The consequences of another nearby variant, substituting an alanine for valine at codon 98 (A98V) is unclear. While some studies have suggested that the frequency of A98V is increased in patients with early onset Type II diabetes [18] and that A98V would be associated with impaired insulin secretion [26] no functional data on this variant is available. Taken together with previous data, our findings with the L107I substitution indicate that at least codons 107-122 are important not only for DNA recognition but also for DNA binding.

In conclusion, we show evidence that a L107I substitution in the HNF1 $\alpha$ gene results in loss-of-function of the protein, and that impaired transcriptional activity of this protein is due to impaired DNA binding. 
Acknowledgements. We thank G.I. Bell for shearing hHNF1 $\alpha /$ pcDNA and J. Takeda for the GLUT2prom/pGl3-basic, Y. Wessman for clinical assistance and R. Gisler for advice about EMSA. We also thank the members of the MODY3 family for participating in this study. This work was supported by grants from the Medical Research Council (31X-10858), EEC GIFT (QLG2-1999-00546), JDF-Wallenberg (JD-12812), the Novo Nordisk Foundation and the Swedish Diabetes Research Foundation to L.G. C.M.C. is supported by a JDRF fellowship.

\section{References}

1. Groop L, Lehto M (1999) Molecular and physiological basis for maturity onset diabetes of youth. Curr Opini Endocrinology and Diabetes 6:157-162

2. Yamagata K, Furuta H, Oda N et al. (1996) Mutations in the hepatocyte nuclear factor-4alpha gene in maturity-onset diabetes of the young (MODY1). Nature 384:458-460

3. Vionnet N, Stoffel M, Takeda J et al. (1992) Nonsense mutation in the glucokinase gene causes early-onset non-insulin-dependent diabetes mellitus. Nature 356:721722

4. Yamagata K, Oda N, Kaisaki PJ et al. (1996) Mutations in the hepatocyte nuclear factor-1alpha gene in maturity-onset diabetes of the young (MODY3). Nature 384:455-458

5. Stoffers DA, Ferrer J, Clarke WL, Habener JF (1997) Early-onset type-II diabetes mellitus (MODY4) linked to IPF1 [letter]. Nat Genet 17:138-139

6. Horikawa Y, Iwasaki N, Hara M et al. (1997) Mutation in hepatocyte nuclear factor-1 beta gene (TCF2) associated with MODY. Nat Genet 17:384-385

7. Malecki MT, Jhala US, Antonellis A et al. (1999) Mutations in NEUROD1 are associated with the development of type 2 diabetes mellitus. Nat Genet 23:323-328

8. Baumhueter S, Mendel DB, Conley PB (1990) HNF-1 shares three sequence motifs with the POU domain proteins and is identical to LF-B1 and APF. Genes Dev 4:372-379

9. Pontoglio M, Barra J, Hadchouel M (1996) Hepatocyte nuclear factor 1 inactivation results in hepatic dysfunction, phenylketonuria, and renal Fanconi syndrome. Cell 84:575585

10. Weber H, Holewa B, Jones EA, Ryffel GU (1996) Mesoderm and endoderm differentiation in animal cap explants: identification of the HNF4-binding site as an activin A responsive element in the Xenopus HNF1alpha promotor. Development 122:1975-1984

11. Vaulont S, Puzenat N, Levrat F, Cognet M, Kahn A, Raymondjean M (1989) Proteins binding to the liverspecific pyruvate kinase gene promoter. A unique combination of known factors. J Mol Biol 209:205-219

12. Takeda J, Kayano T, Fukomoto H, Bell GI (1993) Organization of the human GLUT2 (pancreatic beta-cell and hepatocyte) glucose transporter gene. Diabetes 42:773-777
13. Ellard S (2000) Hepatocyte nuclear factor 1 alpha (HNF-1 alpha) mutations in maturity- onset diabetes of the young. Hum Mutat 16:377-385

14. Nicosia A, Monaci P, Tomei L (1990) A myosin-like dimerization helix and an extra-large homeodomain are essential elements of the tripartite DNA binding structure of LFB1. Cell 61:1225-1236

15. Mendel DB, Hansen LP, Graves MK, Conley PB, Crabtree GR (1991) HNF-1 alpha and HNF-1 beta (vHNF-1) share dimerization and homeo domains, but not activation domains, and form heterodimers in vitro. Genes Dev 5:1042-1056

16. Vaxillaire M, Rouard M, Yamagata K (1997) Identification of nine novel mutations in the hepatocyte nuclear factor 1 alpha gene associated with maturity-onset diabetes of the young (MODY3). Hum Mol Genet 6:583-586

17. Gragnioli CL, Cockburn BN, Kaisaki PJ, Gragnioli F, Marozzi G, Bell GI (1997) Maturity-onset diabetes of the young due to a mutation in the hepatocyte nuclear factor-4 alpha binding site in the promoter of the hepatocyte nuclear factor-1 alpha gene. Diabetes 46:1648-1651

18. Lehto M, Wipemo C, Ivarsson SA (1999) High frequency of mutations in MODY and mitochondrial genes in Scandinavian patients with familial early-onset diabetes. Diabetologia 42:1131-1137

19. Faber OK, Binder C (1977) C-peptide response to glucagon. A test for the residual beta-cell function in diabetes mellitus. Diabetes 26:605-610

20. Beg AA, Finco TS, Nantermet PV, Baldwin AS Jr (1993) Tumor necrosis factor and interleukin-1 lead to phosphorylation and loss of I kappa B alpha: a mechanism for NF-kappa B activation. Mol Cell Biol 13:3301-3310

21. Lehto M, Tuomi T, Mahtani MM (1997) Characterization of the MODY3 phenotype. Early-onset diabetes caused by an insulin secretion defect. J Clin Invest 99:582-591

22. Emens L, Landers D, Moss LG (1992) Hepatocyte nuclear factor $1 \alpha$ is expressed in a hamster insulinoma line and transactivates the rat insulin I gene. Proc Natl Acad Sci USA 89:7300-7304

23. Tomei L, Cortese R, De Francesco R (1992) A POU-A related region dictates DNA binding specificity of LFB1/ HNF1 by orienting the two XL-homeodomains in the dimer. EMBO J 11:4119-4129

24. Bjorkhaug L, Ye H, Horikawa Y, Sovik O, Molven A, Njolstad PR (2000) MODY associated with two novel hepatocyte nuclear factor-1alpha loss-of-function mutations (P112L and Q466X). Biochem Biophys Res Commun 279:792-798

25. Vaxillaire M, Abderrahmani A, Boutin P (1999) Anatomy of a homeoprotein revealed by the analysis of human MODY3 mutations. J Biol Chem 274:35639-35646

26. Urhammer SA, Fridberg M, Hansen T (1997) A prevalent amino acid polymorphism at codon 98 in the hepatocyte nuclear factor-1alpha gene is associated with reduced serum C-peptide and insulin responses to an oral glucose challenge. Diabetes 46:912-916 